\title{
Exergy and Exergo-Environmental analysis of an ORC for a geothermal application
}

\author{
Daniele Fiaschi ${ }^{*}$, Giampaolo Manfrida ${ }^{1}$, Barbara Mendecka ${ }^{2}$, Moein Shamoushaki ${ }^{1}$, and Lorenzo Talluri ${ }^{1}$ \\ ${ }^{1}$ Department of Industrial Engineering, University of Florence, Firenze, Italy \\ ${ }^{2}$ CSGI Interuniversitary Consortium, Firenze, Italy
}

\begin{abstract}
Emissions of contaminants and $\mathrm{CO}_{2}$ are becoming a relevant issue for the development of geothermal energy projects. Organic Rankine (ORC) Cycles present in this light particular appeal in the light of the possibility of total reinjection of the geothermal fluid resource - including Non-Condensable Gases (NCGs). The Castelnuovo (IT) case study conditions are considered - a saturated vapour resource at 10 bar pressure. The performance of the ORC cycle for power generation from this geothermal resource is evaluated through mass and energy balances, stepping up to exergy, Life Cycle Analysis (LCA) and ExergoEnvironmental analyses (EEvA). The applied methodology allows to identify the most critical components of the system and to evaluate the environmental indicators of the system.
\end{abstract}

\section{Introduction}

Geothermal Energy is experiencing continuous growth in the last 50 years, having been acknowledged as an attractive renewable resource, whose utilization with a correct perspective can ensure sustainable development. The use of geothermal energy is certainly appealing where high-quality natural resources exist. However, also mid- and low-temperature resources have demonstrated their attractiveness for production of both heat and power; while the recent development of Enhanced Geothermal Systems (EGS) is promising the possibility of using geothermal energy also where the natural availability of the hydrothermal geo-resource cannot be ensured.

Nowadays, most geothermal power plants are based on the flash steam cycles technology: this means that the resource (geothermal brine, from here on called geofluid) is originally under pressurized liquid state in the reservoir. A pressure reduction (which may take place either within the well or into a separator as a part of the surface equipment, - the latter with adjustable pressure) determines the generation of saturated steam, which is directly expanded into a steam turbine [1]. Some locations rely on a superheated (or saturated) direct steam resource; this is the case of the historical site Larderello-Travale in Italy [2]. A small number of plants are applying binary cycles technology belonging to
Organic Rankine Cycles (ORC). Here, the working fluid is a chemical substance or mixture (usually a suitable hydrocarbon; in some cases, refrigerants or siloxanes) which is flowing in a secondary loop, heated by the geofluid in liquid or two-phase condensing conditions [3]. Since the eighties, reinjection of the liquid brine is extensively practiced in geothermal fields: this has simplified the task of maintaining the resource for longterm utilization, as is demonstrated in some relevant cases $[4,5]$. As the geo-resource is also generally used as a coolant in a wet tower/condenser arrangement with extensive recirculation, evaporative losses of water are consistent and make-up water must often be provided externally.

Even though most of the geo-fluid is water, a problem arises in connection with the presence of NonCondensable Gases (NCGs). Most of these are Carbon Dioxide $\left(\mathrm{CO}_{2}\right)$, but minor constituents are present, such as $\mathrm{H}_{2} \mathrm{~S}, \mathrm{CH}_{4}, \mathrm{NH}_{3}$, and Boron. Moreover, depending on the properties of the rocks, the geo- resource is very rich in salts and sometimes minor contaminants (heavy metals, such as $\mathrm{Hg}$;); the presence of salts is technically important because it can put limits on the lowest allowed reinjection temperature, which cannot be too low in order to avoid precipitation of salts [6]. At present, NCGs are directed to the wet cooling tower, which has a highly buoyant plume and allows a good dispersion of gases. In Italian power plants, contaminants are

\footnotetext{
* Corresponding author: daniele.fiaschi@unifi.it
} 
effectively removed before mixing at the tower, using a modern chemical scrubbing process, namely AMIS ${ }^{\circledR}$, [7]. However, the Italian resource has typical $\mathrm{CO}_{2}$ levels from 2 to $8 \%$ or more, determining a greenhouse emission factor, in strict terms, in the range between 100 and $400 \mathrm{gCO}_{2} / \mathrm{kWh}$ [8]. This is indeed a "natural" emission, part of which would probably reach the surface anyway because of natural fracture patterns [9]. However, it is true that local utilization of geothermal energy determines a preferential pathway for releasing larger flow rates of $\mathrm{CO}_{2}$ to the atmospheric environment (the upper values are close to those of advanced natural gas fuelled power plants).

For the above reasons, taking advantage of a favourable scheme of incentives applied by the Italian government for resources having such difficult conditions for utilization, a number of new operators on the power market are proposing new solutions for the conversion of geothermal energy: these are based on ORCs but include the complete reinjection (or mineralization) of $\mathrm{CO}_{2}$.

\section{The Castelnuovo project}

The Castelnuovo pilot concession (presently at the level of geothermal research exploration) is aimed at demonstrating the possibility of complete reinjection of the resource (brine and NCGs) in the local geothermal reservoir. According to Italian laws, these pilot plants must be limited to $5 \mathrm{MWe}$ power output. The Castelnuovo reservoir, however, is considerably large, so that the preliminary reservoir simulations have shown that it has the capacity of effectively retaining the reinjected gas flow rate, which - with careful management - should be confined into the permeable rock porosity or in local gas cavities, helping to maintain the original reservoir pressure. The resource is expected to be saturated vapour at a pressure within the $60-80$ bars range, $280^{\circ} \mathrm{C}$ temperature at about $3500 \mathrm{~m}$ depth. At the wellhead, the expected resource conditions are 10.3 bars pressure and $180{ }^{\circ} \mathrm{C}$ temperature. The NCG mass content is estimated at about $8 \%$, of which about $7.8 \%$ is $\mathrm{CO}_{2}$ and $0.2 \% \mathrm{H}_{2} \mathrm{~S}$. The well layout consists of 2 production and 1 reinjection wells (the latter in the proximity of the powerhouse).

A general scheme of the wells/power cycle arrangement is shown in Figure 1. A subcritical recuperative ORC power cycle using $\mathrm{R} 1233 \mathrm{zd}(\mathrm{E})$ as working fluid is fed by the geo-fluid through a condensing heat exchanger (MHE). MHE is pressurized at about 10 bars. Within MHE, the NCGs are released at the top while the condensed brine is released from the bottom and directed to the reinjection wells.

The operating scheme adopted in Castelnuovo is original and considers a novel technology for $\mathrm{CO}_{2}$ reinjection [10]. An intercooled compressor train (three stages in the present configuration) powers the gas reinjection. Intercooling allows limiting the compressor power; moreover, in the first cooling stages (pre-cooler PreC and intercooler IC1) most of the water vapour is condensed; this further limits the required power, and simplifies some technical issues as part of the $\mathrm{H}_{2} \mathrm{~S}$ (and $\mathrm{CO}_{2}$ ) is retained in the liquid.

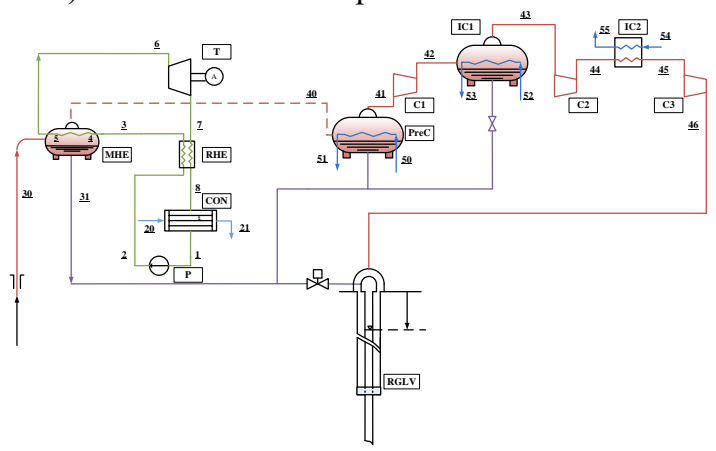

Fig. 1. Schematic of Castelnuovo power plants and wells/NCG reinjection arrangement

\section{Power plant model}

The power plant calculations were based on standard steady-state mass and energy balances for open systems. The working fluid properties were taken from a reliable source [11] (utilizing reduced Helmhotz free energy EOS), while specific models were developed for accurate calculation of the geo-fluid properties (IAPWS formulation, depending on the $\mathrm{CO}_{2}$ content) [12]. The input data are summarized in Table 1 and the results of the calculations are collected in Table 2.

Table 1. Assumed design input data for the Castelnuovo power plant

\begin{tabular}{cccc}
\hline Parameter & Unit & Symbol & Value \\
\hline $\begin{array}{c}\text { Reference } \\
\text { temperature } \\
\text { Turbine }\end{array}$ & ${ }^{\circ} \mathrm{C}$ & $T_{0}$ & 15 \\
isentropic & $\%$ & $\eta_{t}$ & 88 \\
efficiency \\
$\begin{array}{c}\text { Pump } \\
\text { isentropic } \\
\text { efficiency }\end{array}$ & $\%$ & $\eta_{p}$ & 85 \\
$\begin{array}{c}\text { Geothermal } \\
\text { fluid inlet }\end{array}$ & ${ }^{\circ} \mathrm{C}$ & $T_{30}$ & 180 \\
temperature & & & \\
$\begin{array}{c}\text { Geothermal } \\
\text { fluid inlet } \\
\text { pressure }\end{array}$ & $\mathrm{kPa}$ & $P_{30}$ & 1000 \\
$\begin{array}{c}\text { Net Power } \\
\text { Output }\end{array}$ & $\mathrm{kW}$ & $\mathrm{W}_{\text {net }}$ & 5000 \\
\hline
\end{tabular}

Table 2. Main calculated performance parameters for the Castelnuovo Power Plant

\begin{tabular}{|c|c|c|c|}
\hline Parameter & Unit & Symbol & Value \\
\hline $\begin{array}{l}\text { Geothermal } \\
\text { mass flow rate }\end{array}$ & $\mathrm{kg} / \mathrm{s}$ & $\dot{m}_{g e o}$ & 11.09 \\
\hline $\begin{array}{c}\mathrm{CO}_{2} \text { mass flow } \\
\text { rate }\end{array}$ & $\mathrm{kg} / \mathrm{s}$ & $\dot{m}_{C O_{2}}$ & 0.8869 \\
\hline $\begin{array}{l}\text { Power plant } \\
\text { efficiency }\end{array}$ & $\%$ & $\eta$ & 18.51 \\
\hline $\begin{array}{l}\text { Heat input } \\
\text { from } \\
\text { Geothermal } \\
\text { Fluid } \\
\end{array}$ & $\mathrm{kW}$ & $\dot{Q}_{H E}$ & 26894 \\
\hline
\end{tabular}




\section{Reinjection train calculations}

As shown in Table 2, with a geo-resource flow rate of $11.09 \mathrm{~kg} / \mathrm{s}$ and an NCGs mass content of $8 \%$, the compressor train must handle a gas flow rate of 0.8869 $\mathrm{kg} / \mathrm{s}$. This must be compressed at $5841 \mathrm{kPa}$ design pressure of, corresponding to mixing conditions in a deep-hole reverse gas lift valve (RGLV) placed at a nominal depth of about $600 \mathrm{~m}$ from the surface.

The calculation of the compressor train assumes steadystate flow in the reinjection well, both on the external annulus transporting the NCGs, and in the inner pipe carrying the liquid. The configuration of the compressor train here presented has 3 compressor stages, one precooler and two intercoolers, which allow a significant reduction of the required compression power.

The results of the calculations for the NCG compressor train are collected in Table 3.

Table 3. Main calculated performance parameters for the Castelnuovo Power Plant

\begin{tabular}{|c|c|c|c|}
\hline Point & \multicolumn{2}{|c|}{$\begin{array}{c}\text { Temperature } \\
{\left[{ }^{\circ} \mathrm{C}\right]}\end{array}$} & Pressure [kPa] \\
\hline 40 & \multicolumn{2}{|c|}{90} & 1000 \\
\hline 41 & \multicolumn{2}{|c|}{65} & 1000 \\
\hline 42 & \multicolumn{2}{|c|}{119.4} & 1801 \\
\hline 43 & \multicolumn{2}{|c|}{60} & 1801 \\
\hline 44 & \multicolumn{2}{|c|}{114.4} & 3243 \\
\hline 45 & \multicolumn{2}{|c|}{60} & 3243 \\
\hline 46 & \multicolumn{2}{|c|}{115.1} & 5841 \\
\hline Parameter & Unit & Symbol & Value \\
\hline $\begin{array}{c}\text { Heat Rate } \\
\text { PreC }\end{array}$ & $\mathrm{kW}$ & $\dot{Q}_{P C}$ & 20.78 \\
\hline Power C1 & $\mathrm{kW}$ & $\dot{W}_{C 1}$ & 41.81 \\
\hline Heat Rate IC1 & $\mathrm{kW}$ & $\dot{Q}_{I C 1}$ & 51.53 \\
\hline Power C2 & $\mathrm{kW}$ & $\dot{W}_{C 2}$ & 39.88 \\
\hline Heat Rate IC2 & $\mathrm{kW}$ & $\dot{Q}_{I C 2}$ & 50.71 \\
\hline Power C3 & $\mathrm{kW}$ & $\dot{W}_{C 3}$ & 37.56 \\
\hline
\end{tabular}

\section{Exergy analysis}

Exergy is defined as the maximum work that can be obtained by bringing the state of a system to equilibrium with that of the environment [13]. In the present study, the exergy analysis [14] includes the detailed calculation of destructions and losses (1), of the exergy efficiency (3) and exergy destruction ratio (4) in each k-th component of the, as well as for the overall system. Based on the function of a component, appropriate costs can be allocated to the fuel $(\mathrm{F})$, product $(\mathrm{P})$, destructions (D) or losses (L). In general terms, the exergy balance is as follows:

$$
\sum \dot{\mathrm{Ex}_{F, k}}=\sum \dot{\mathrm{Ex}}_{\mathrm{P}, \mathrm{k}}+\sum \mathrm{Ex}_{D, k}+\sum \mathrm{Ex}_{\mathrm{L}, \mathrm{k}}
$$

The physical exergy of each state point is considered as:

$$
\dot{\mathrm{Ex}}_{\mathrm{i}}=\dot{\mathrm{m}}_{\mathrm{i}}\left[\left(\mathrm{h}_{\mathrm{i}}-\mathrm{h}_{\mathrm{o}}\right)-\mathrm{T}_{\mathrm{o}}\left(\mathrm{s}_{\mathrm{i}}-\mathrm{s}_{\mathrm{o}}\right)\right]
$$

where $m_{i}$ is the mass of substance under consideration; $h_{i}, s_{i}$ are, respectively, the enthalpy and entropy of the considered stream of matter; $h_{0}, s_{0}$ are the enthalpy and entropy of this matter in equilibrium state with the environment at the reference temperature $T_{0}$ and pressure $p_{o}$.

The Exergy efficiency of each component is defined as:

$$
\varepsilon_{k}=\frac{\dot{\mathrm{Ex}_{P}}}{\dot{\mathrm{Ex}_{F}}}
$$

while the exergy destruction ratio is calculated as:

$$
\chi_{k}=\frac{\dot{\mathrm{Ex}}}{\dot{\mathrm{Ex}_{D}, t o t}}
$$

\section{LCA and Exergo-Environmental analysis}

The Life Cycle Assessment (LCA) carried out in this study, even if it is applied to a design case and not to an existing plant, follows the methodological framework defined in ISO 14040 standard [15, 16]. A main stage of the LCA is to build the Life Cycle Inventory (LCI) of the plant; the LCI applied to all plant components, allows the assessment of the environmental costs of construction and operation. An open-source software, OpenLCA 1.10 [17] and the Ecoinvent 3.6 database [18] were used for the background data modelling and environmental assessment. ReCiPe 2016 method with the hierarchist $(\mathrm{H})$ perspective was used to characterize the environmental impacts at midpoint and endpoint level. The endpoints are related to three areas of protection: human health, ecosystem quality and resource scarcity.

Further, the results were normalized with respect to the EU area. Finally, weighting factors were applied to quantify the single score environmental impact of each component of the system [19].

The component - related environmental impact $\dot{Y}_{k}$, was calculated including the following system boundary stages: 1) production of raw materials and manufacturing of components (CO), 2) operational and maintenance phase (OM) 3) end of life phase, that includes decommissioning and recycling or disposal of components (EoL) and 4) transportation above mentioned stages.

$$
\dot{Y}_{k}=\dot{Y}_{C O}+\dot{Y}_{O M}+\dot{Y}_{E O L}
$$

Concerning the definition of the system boundaries, a $1 \%$ cut-off was set. The functional unit of the LCA was set as $1 \mathrm{MWh}$ of net output electricity. A 30 years lifetime was assumed. In the construction phase, geothermal deep well drilling, collection pipelines and power plant machinery were taken into account. Power plant buildings and internal pipelines were neglected. Conventional large - scale flash geothermal systems emit various gases such as $\mathrm{CO}_{2}, \mathrm{H}_{2} \mathrm{~S}, \mathrm{CH}_{4}$ in the operation stage. With the present binary cycle, full reinjection was considered means that no emissions from geothermal fluid are present during the operational stage. However, the environmental impact of the working fluid leakage is taken into account assuming an annual loss rate of $0.5 \%$ of the total fluid amount [20]. The end-of-life stage includes wells closure.

The Exergo-Environmental Analysis (EEvA) represents the natural follow-up of the LCA: EEvA starts from the allocation of the LCI to all powerplant components and analyzes the progressive build-up of the environmental costs along with the processes. The EEvA is carried out similarly to the thermo-economic analysis [21], replacing the environmental costs (Recipe 2016 Single 
Scores) to the economic costs - still referring to the exergy unit. The environmental cost rates related to each j-stream $\dot{B}_{j}(\mathrm{Pts} / \mathrm{s})$ are allocated to their exergy content $E x_{j}(\mathrm{MJ}$ or MWh) to evaluate the specific environmental impacts $b_{j}$ (Pts/MJ; or Pts/MWh referring to the final cost of electricity) through:

$$
b_{j}=\frac{\dot{B_{j}}}{\dot{E x_{j}}}
$$

This methodology is based on the solution of impact balances performed for each $\mathrm{k}$ - th component, using (7):

$$
\sum \dot{B}_{j, k, \text { in }}+\dot{Y}_{k}=\sum \dot{B}_{j, k, \text { out }}
$$

Where $\dot{Y}_{k}$ (mPts/s) is the environmental impact rate associated with the construction, O\&M and end of life stages. This parameter is connected with the LCA results, which are expressed considering $1 \mathrm{MWh}$ of electricity as a functional unit (Pts/MWh). In practice, the single score impact was multiplied by the yearly productivity; after that, an impact rate $\dot{Y}_{k}$ was achieved. The environmental costs per unit of exergy (Pts/MWh) of product $b_{P, k}$ and fuel $b_{F, k}$ were defined as in the case of EEvA. This allows the evaluation of the environmental cost rate $\dot{B}_{D, k}(\mathrm{mPts} / \mathrm{s})$ associated with the exergy destruction occurring inside each component through:

$$
\dot{B}_{D, k}=b_{F, k} \cdot \dot{E} x_{D, k}
$$

An exergo-environmental factor $f_{d, k}$, representing the percentage contribution of $\dot{Y}_{k}$ compared to the total $\dot{B}_{D, k}+\dot{Y}_{k}$, can be calculated using (9):

$$
f_{d, k}=\frac{\dot{Y}_{k}}{\dot{B}_{D, k}+\dot{Y}_{k}}
$$

The relative difference of the specific environmental impacts for the $\mathrm{k}$-th component is given in the following equation (10):

$$
r_{d, k}=\frac{b_{P, k}-b_{F, k}}{b_{F, k}}
$$

\section{Results}

\subsection{Exergy analysis}

Figure 2 shows the non-dimensional exergy destruction for each component of the cycle. As shown, the highest relative exergy destruction comes from the geothermal heat exchanger. This result means that an improved matching of the heat capacity of the cold and hot sides of the MHE main heat exchanger can have a relevant effect on the system performance. After the MHE, the condenser exergy loss and the turbine exergy destruction represent the largest contributions compared to the remaining components.

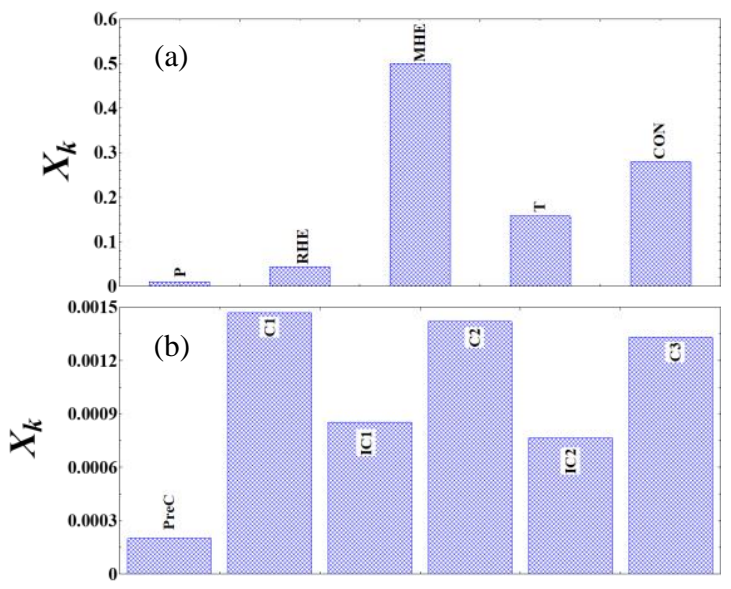

Fig. 2. Non-dimensional exergy destruction for each component (a) ORC plant, (b) Re-compression train

\subsection{Life Cycle Assessment and Exergo- Environmental analysis}

The contributions of the power plant components in the total impact are presented in Figure 3. The total environmental impact of electricity produced in the analyzed binary power plant is $3.20 \mathrm{Pts} / \mathrm{MWh}$.

Furthermore, the highest impact value (2.81 Pts/MWh) is assigned to geothermal wells construction, that contributes for nearly $87.6 \%$ to the total impact. This is mainly due to diesel combustion during drilling, cement and steel for the well casing. The environmental impact associated to the working fluid accounts for $2.3 \%$ of the total impact ( $0.075 \mathrm{Pts} / \mathrm{MWh})$. The overall contribution of the power plant components to the total associated environmental impact is rather small (below $10 \%$ ). Of the subcritical regenerative ORC power cycle components, the turbine/generator has the highest environmental impact $(0.199 \mathrm{Pts} / \mathrm{MWh})$, followed by the main heat exchanger ( $0.054 \mathrm{Pts} / \mathrm{MWh})$ and air-cooled condenser $(0.048 \mathrm{Pts} / \mathrm{MWh})$, whose impact is mainly due to steel, copper and aluminium for construction. The NCG reinjection train, consisting of the set of compressors and intercoolers, accounts for $0.2 \%(0.006$ $\mathrm{Pts} / \mathrm{MWh}$ ) of the total impact. The environmental impact of other technologies powered by renewables is generally higher than the one here achieved. According to the Ecoinvent database, the estimates of ReCiPe 2016 (H) single score results are varying from 14.3 to 23.8 Pts/MWh for hydropower and photovoltaic system, respectively [18].

Table 4. Summary of equipment sizes and materials inventory for the $5 \mathrm{MW}$ (net power) ORC.

\begin{tabular}{ccccc}
\hline Component & $\begin{array}{c}\dot{\boldsymbol{Y}}_{\boldsymbol{k}} \\
(\mathbf{P t s} / \mathbf{h})\end{array}$ & $\begin{array}{c}\dot{\boldsymbol{B}}_{\boldsymbol{D}, \boldsymbol{k}} \\
(\mathbf{P t s} / \mathbf{h})\end{array}$ & $\boldsymbol{f}_{\boldsymbol{D}, \boldsymbol{k}}$ & $\boldsymbol{r}_{\boldsymbol{D}, \boldsymbol{k}}$ \\
\hline $\mathrm{P}$ & 0.0203 & 0.1272 & 0.1379 & 0.1883 \\
$\mathrm{RHE}$ & 0.0470 & 0.1180 & 0.2848 & 0.3741 \\
$\mathrm{MHE}$ & 0.4669 & 2.7317 & 0.1459 & 0.3157 \\
$\mathrm{~T}$ & 1.0616 & 1.5498 & 0.4065 & 0.1994 \\
$\mathrm{CON}$ & 0.3405 & 2.7014 & 0.1119 & - \\
PreC & 0.0227 & 0.0135 & 0.6271 & 1.4440 \\
C1 & 0.0024 & 0.0161 & 0.1308 & 0.1774 \\
IC1 & 0.0127 & 0.0061 & 0.6753 & 1.3770 \\
C2 & 0.0024 & 0.0155 & 0.1340 & 0.1805 \\
IC2 & 0.0125 & 0.0064 & 0.6626 & 1.2030 \\
C3 & 0.0024 & 0.0146 & 0.1399 & 0.1810 \\
\hline
\end{tabular}




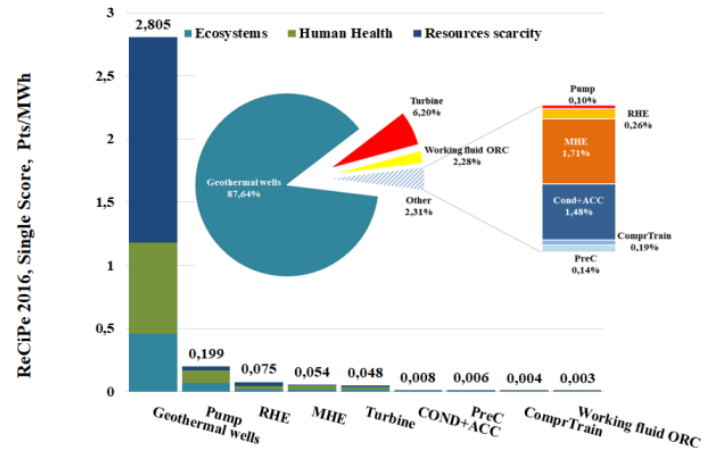

Fig. 3. Single Score environmental impacts of the analysed systems.

The $f_{D, k}$ factor identifies the relevance of the impact coming from the exergy destruction of the $\mathrm{k}$-th component. It is evident that for almost all of power cycle components (excluding geothermal wells) the environmental impact is mainly due to exergy destruction $\dot{B}_{D, k}$, whereas component construction $\dot{Y}_{k}$ contributes much less.

Concerning the total environmental impact $\left(\dot{Y}_{k}+\dot{B}_{D, k}\right)$, the main heat exchanger is found to be the most impacting: among the power cycle machinery equipment, it represents $34 \%$ of the total score, $15 \%$ only of this total impact $\left(f_{D, k}\right)$ is due to the environmental cost of component construction $\dot{Y}_{k}$, whereas $85 \%$ is attributable to the exergy destruction $\left(\dot{B}_{D, k}\right)$. In fact, the thermodynamic irreversibility in this component is the highest, as can be observed in Figure 2. Another component significantly contributing to the environmental impact (33\%) is the condenser, with a high relative environmental impact due to the exergy loss (89\%). In addition, a relevant environmental contribution to exergy destruction $(1.55 \mathrm{Pts} / \mathrm{h})$ is calculated for the turbine, which sums to the third in order of significance contribution to the environmental cost of construction $(2.62 \mathrm{Pts} / \mathrm{h}$ i.e. $28 \%$ of the total impact).

The relative difference of specific environmental impacts $r_{D, k}$ is an indicator of the environmental quality of a component, allowing to assess the potential of reducing its environmental impact. As indicated in Table 4, the air-cooled condenser and precooler may address the possibility of an environmental impact reduction at relatively low cost.

\section{Conclusions}

The issues related to the environmental concerns related to the traditional exploitation of geothermal resources greatly increased the interest towards total reinjection geothermal powerplants. This technology belongs to binary power cycles, that are fed by a closed loop exploiting the heat only of the geothermal resource, which is completely reinjected thus avoiding the release of pollutants to the atmosphere. The investigation of such a possible $5 \mathrm{MW}$ pilot plant proposal is planned, under the cap of H2020 GECO Project, just in the core of one of the most important geothermal areas worldwide, namely Larderello in Italy, where since one century the traditional exploitation of the resource to produce electricity is practised. The Geo-fluid composition, rich in NCGs (up to $10 \%$ mass), makes the reinjection challenging.

In this manuscript, a complete analysis of a possible design test case - the power plant planned in Castelnuovo (IT), is here presented. The analysis, starting from a thermodynamic approach, is extended to include Exergy, Life Cycle Assessment and ExergoEnvironmental aspects. It allows the full assessment of LCA and exergoenvironmental aspects related to the utilization of a binary $5 \mathrm{MW}$ ORC with total reinjection of the geothermal fluid.

The selected case study represents a novel application in geothermal energy - a first-of-a-kind powerplant applying complete reinjection of non-condensable gases (NCGs). The powerplant is an ORC working with $\mathrm{R} 1233 z d(\mathrm{E})$, with integrated NCGs recompression train, into a layout which minimizes the energy required for the recompression of NCGs into the reinjection well at $600 \mathrm{~m}$ depth.

Starting from thermodynamics, the exergy analyses are carried out. Successively, the LCA is applied to the geothermal power system. It is the basis to build up the exergoenvironmental analysis, which gives the share of the environmental impact points of the whole system components. The exergy and the exergo-environmental analyses indicate the pathway to general performance improvement, identifying within the system, the components responsible for the largest irreversibility, contribution to build up of the environmental cost. Following is the main summary of results:

- The largest exergy destructions source is the HEGeo (50\%), followed by the ORC turbine $(15 \%)$. The condenser is responsible for the highest exergy loss $(28 \%)$.

- The yearly single score environmental impacts put in evidence that the total environmental impact of electricity generation (i.e. binary cycle) is 3.2 $\mathrm{Pts} / \mathrm{MWh}$, which is generally lower than all other renewables. The highest impact is due to the well construction, with $2.81 \mathrm{Pts} / \mathrm{MWh}$; the overall contribution of the power plant machinery components is relatively small (less than $10 \%$ ).

- The exergoenvironmental analysis evidenced that highest impacting components, after the well, is the main heat exchanger (HEGeo), accounting for $34 \%$ of total power cycle machinery equipment, followed by the condenser.

The results demonstrate that the powerplant is capable of producing electricity at an interesting cost and with sustainability indexes competitive with the best renewable energy technologies.

\section{Acknowledgments}

The present research represents dissemination of activities performed by University of Florence in WP2, 4 and 9 of the H2020 GECO project (Grant Agreement n ${ }^{\circ} 818169$ ). 


\section{Nomenclature}

\begin{tabular}{cl}
$\dot{B}$ & Environmental cost rates, $(\mathrm{Pts} / \mathrm{s})$ \\
$b$ & Specific environmental cost, $(\mathrm{Pts} / \mathrm{kWh})$ \\
$E E v a$ & Exergo-Environmental Analysis \\
$E x$ & Exergy rate, $(\mathrm{kW})$ \\
$f_{d}$ & Exergo-environmental factor \\
$h$ & Specific enthalpy, $(\mathrm{kJ} / \mathrm{kg})$ \\
$L C A$ & Life Cycle Assessment \\
$L C I$ & Life Cycle Inventory \\
$\dot{m}$ & Mass flow rate, $(\mathrm{kg} / \mathrm{s})$ \\
$N C G s$ & Non-Condensable Gases \\
$P$ & Pressure, $(\mathrm{kPa})$ \\
$\dot{Q}$ & Heat rate, $(\mathrm{kW})$ \\
$r$ & Relative difference of the specific \\
& environmental impacts \\
$s$ & Entropy, $(\mathrm{kJ} / \mathrm{kgK})$ \\
$T$ & Temperature, $\left({ }^{\circ} \mathrm{C}\right)$ \\
$\dot{W}$ & Power, $(\mathrm{kW})$ \\
$\dot{Y}$ & Environmental impact rate, $(\mathrm{mPts} / \mathrm{s})$ \\
Greek & \\
$\eta$ & Efficiency \\
$\varepsilon$ & Effectiveness \\
Subscripts & \\
$t$ & Turbine \\
$p$ & Pump \\
$g e o$ & Geothermal \\
$P C$ & Pre-cooler \\
$C$ & Compressor \\
$I C$ & Intercooler \\
$H E$ & Heat exchanger \\
$C o n d$ & Condenser \\
$L$ & Loss \\
$D$ & Destruction \\
$P$ & Product \\
$F$ & Fuel \\
$t o t$ & Total \\
$i$ & inlet \\
$e$ & exit \\
0 & Ambient \\
& \\
\hline &
\end{tabular}

\section{References}

1. DiPippo R.: Geothermal power plants: Principles, Applications, Case Studies and Environmental Impact, $3^{\text {rd }}$ ed., Butterworth-Heinemann, Elsevier, Oxford, England, (2012).

2. DiPippo R.: Geothermal power plants: Evolution and performance assessments, Geothermics, 53, (2015), 291-307.

3. Fiaschi D., Manfrida G., Rogai E., Talluri L.: Exergoeconomic analysis and comparison between ORC and Kalina cycles to exploit low and medium-high temperature heat from two different geothermal sites, Energy Conversion and Management, 154, (2017), 503516.

4. Kaya E., Zarrouk S.J., O'Sullivan M.J.: Reinjection in geothermal fields: A review of worldwide experience, Renewable and Sustainable Energy Reviews, 15, (2011), 47-68.

5. Diaz A.R., Kaya E., Zarrouk S.J., Reinjection in geothermal fields: A review of worldwide update, Renewable and Sustainable Energy Reviews, 15, (2016), 105-162.

6. Zarrouk S.J., Woodhurst B.C., Morris C.: Silica scaling in geothermal heat exchangers and its impact on pressure drop and performance: Wairakei binary plant, New Zealand, Geothermics, 51, (2014), 445-459.
7. Baldacci A., Mannari M., Sansone F.: Greening of Geothermal Power: An Innovative Technology for Abatement of Hydrogen Sulphide and Mercury Emission, Proceedings, World Geothermal Congress 2005, Antalya, Turkey, (2005).

8. Sullivan J.L., Clark C.E., Han J., Wang M.: Life-Cycle Analysis Results of Geothermal Systems in Comparison of Other Power Systems, Report, Energy Systems Division of Argonne national laboratory, US Department of Energy, Chicago, US (2010).

9. Bruscoli L., Fiaschi D., Manfrida G., Tempesti D.: Improving the Environmental Sustainability of Flash Geothermal Power Plants - A Case Study, Sustainability, 7, (2015), 15262-15283.

10. Shafaei M.J., Abedi J., Hassanzadeh H., Chen Z.: Reverse gas-lift technology for $\mathrm{CO} 2$ storage into deep saline aquifers, Energy, 45, (2012), 840-849.

11. Klein S.A., Nellis G.F.: Mastering EES, f-Chart software, (2012).

12. Colucci V., Fiaschi D., Leveni M., Manfrida G., Talluri L.: Thermodynamic model of geothermal resources for low-medium temperature energy conversion process optimization, Chemical Engineering Transactions, 76, (2019).

13. Kotas, T., The Exergy Method of Thermal Plant Analysis, Elsevier, 1985

14. Bejan A., Tsatsaronis G., Moran M.J.: Thermal Design and Optimization, John Wiley \& Sons, (1996).

15. ISO (2006a). ISO 14040: Environmental management: Life-cycle assessment: Principles and framework. International Organization for Standardization, Geneva, Switzerland, available at http://www.iso.org (last accessed on 12/07/2019).

16. ISO (2006b). ISO 14044: Environmental management: Life-cycle assessment: Requirements and guidelines. International Organization for Standardization, Geneva, Switzerland. available at http://www.iso.org (last accessed on 12/07/2019).

17. Di Noi C., Ciroth A., Srocka M.: OpenLCA 1.7, Comprehensive User Manual, GreenDelta GmbH, Berlin, Germany, (2017).

18. Wernet G., Bauer C., Steubing B., Reinhard J., MorenoRuiz E., Weidema, B.: The ecoinvent database version 3 (part I): overview and methodology, The International Journal of Life Cycle Assessment, 21, (2016), 12181230.

19. Huijbregts M.A.J., Steinmann Z.J.N., Elshout P.M.F., Stam G., Verones F., Vieira M.D.M., Hollander A., Zijp M., Van Zelm R., ReCiPe 2016, A harmonized life cycle assessment method at midpoint and endpoint level, Report, National Institute for Public Health and the Environment, The Netherlands, (2016).

20. Ding Y., Liu C., Zhang C., Xu X., Li Q., Mao L.: Exergoenvironmental model of Organic Rankine Cycle system including the manufacture and leakage of working fluid, Energy, 145, (2018), 52-64.

21. Meyer L, Tsatsaronis G, Buchgeister J, Schebek L. Exergoenvironmental analysis for evaluation of the environmental impact of energy conversion systems. Energy, 34, (2009), 52-64, 75-89. 